\title{
Advancing Coordinated Care in Four Provincial Healthcare Systems: \\ Evaluating a Knowledge-Exchange Intervention
}

\author{
Avancement des soins coordonnés dans quatre \\ systèmes de santé provinciaux : évaluation d'une \\ intervention d'échange de connaissances
}

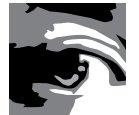 \\ GRACE WARNER, PHD \\ Research Associate, Atlantic Health Promotion Research Centre \\ Associate Professor, School of Occupational Therapy \\ Dalhousie University \\ Halifax, NS \\ RENEE LYONS, PHD \\ Bridgepoint Chair in Complex Chronic Disease Research, \\ Bridgepoint Health \\ Professor Dalla Lana School of Public Health, University of Toronto \\ Toronto, Ontario \\ VICTORIA PARKER, DBA \\ Associate Professor, School of Public Health \\ Boston University \\ Boston, $M A$ \\ STEPHEN PHILLIPS, MD \\ Department of Medicine (Division of Neurology), Dalhousie University \\ Stroke Neurologist, Queen Elizabeth II Health Science Centre, Capital District Health Authority \\ Halifax, NS
}




\begin{abstract}
Objectives: This research project created and evaluated a knowledge-exchange intervention designed to facilitate an increase in organizational readiness for implementing coordinated stroke care in four primarily rural provincial healthcare systems.

Intervention: Knowledge brokers were linked to networks within, across and outside the provinces to support, inform and disseminate best practice recommendations for coordinated stroke care within the provincial healthcare systems.

Findings: The intervention increased awareness and dissemination of recommendations, which stimulated the implementation of coordinated stroke care. Similar knowledge-exchange interventions might work in other healthcare jurisdictions with similar demographics, to promote evidence-informed improvements in healthcare.
\end{abstract}

\title{
Résumé
}

Objectifs : Le projet de recherche visait la création et l'évaluation d'une intervention d'échange de connaissances conçue pour faciliter une meilleure préparation organisationnelle pour la mise en œuvre de soins coordonnés pour le traitement d’accidents cérébrovasculaires dans quatre systèmes de santé provinciaux principalement ruraux.

Intervention: Un courtier de connaissances était en lien avec les réseaux (internes, interprovinciaux et extraprovinciaux) qui ont appuyé, éclairé et diffusé des recommandations pour les meilleures pratiques en matière de soins coordonnés pour les accidents cérébrovasculaires au sein des systèmes de santé provinciaux.

Résultats : L'intervention a permis d'accroître la sensibilisation aux recommandations ainsi que leur diffusion, ce qui a stimulé la mise en place de soins coordonnés pour traiter les accidents cérébrovasculaires. Des interventions similaires d'échange de connaissances pourraient fonctionner dans d'autres systèmes de santé qui présentent des données sociodémographiques similaires, et ce dans le but de promouvoir les améliorations éclairées par les données probantes dans les services de santé.

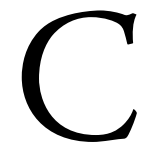
ONTEMPORARY BEST PRACTICE RECOMMENDATIONS FOR STROKE CARE, OUTLINED in detail in the Canadian Stroke Strategy, advocate for the coordination of services across the continuum of care, from prevention through to diagnosis, treatment and community re-integration (Canadian Stroke Strategy 2008; Lindsay et al. 2008). Key recommendations in the Canadian Stroke Strategy are the timely administration of thrombolytic therapy after the patient has been correctly diagnosed as having an acute ischaemic stroke through a CT brain scan and the provision of multidisciplinary care via a specialized stroke unit (stroke-unit care). Despite the release of best practice recommendations by the Canadian Stroke Strategy, implementation is a major challenge. Coordinated stroke care requires changes across divergent healthcare sectors (e.g., emergency care staff, administrators, policy makers) 
and communication between numerous healthcare professionals (e.g., physicians, rehabilitation professionals, paramedics).

Often these multisectoral, interprofessional changes can be facilitated when health system administrators, who are responsible for creating and updating protocols, are aware of the best practice recommendations and support their implementation. However, administrators need the approval of their organizations for them to support implementation of best practice recommendations. There is often little organizational readiness within the health system to update current protocols unless the public, or individuals within the healthcare system, demand that the standards of care be improved.

Organizational readiness has been defined as a situation in which a majority of the individuals within the organization are psychologically and behaviourally prepared to initiate change (Weiner et al. 2008; Weiner 2009). Readiness has been shown to be an important precursor to making system-level changes, such as implementing best practice recommendations (Greenhalgh et al. 2004). Targeted strategies can increase organizational readiness for change by improving organizational members' awareness about the need to make changes, their knowledge about what the changes would look like, and confidence that the envisioned change can be achieved (Weiner 2009). In order to increase the organizational readiness for implementing coordinated stroke care, a research project featuring a knowledge-exchange intervention was developed and implemented in four provincial healthcare systems.

The knowledge-exchange intervention consisted of establishing a knowledge broker in each province, and linking brokers to networks within, across and outside their provincial healthcare systems. A knowledge broker has been defined as someone who brings people together, builds relationships, shares ideas and facilitates a debate around the research evidence (Dobbins et al. 2009). Networks have been described as links that "improve the flow of information and knowledge across disciplines and sectors" (Contractor and Monge 2002). Networks create opportunities for exchanging information and social networking, both of which have been associated with facilitating innovation within healthcare systems (Greenhalgh et al. 2004).

In this research project, the knowledge broker was the primary node of the network, and was used as a conduit to increase the flow of information among members. In Canada, the provincial departments of health (DOHs) are commonly responsible for creating protocols and distributing funds from the provincial governments to implement the protocols; therefore, the DOHs were an essential component of the network. The aim of the knowledge-exchange intervention was to increase organizational readiness for coordinated stroke care within the provincial healthcare systems by increasing members' (a) awareness about the need for change to improve current stroke care services; (b) knowledge of best practice recommendations for coordinated stroke care, as these outline what improved care would look like; and, (c) confidence that they could achieve improved stroke care by providing links with key individuals who would support change. 


\section{Methods \\ Setting}

The knowledge-exchange intervention was conducted as a collaborative research project (Denis and Lomas 2003; Lomas 2000) with four provincial DOHs and the Heart and Stroke Foundations (HSFs) in Atlantic Canada (i.e., New Brunswick, Newfoundland and Labrador, Nova Scotia and Prince Edward Island). The reason the project partnered with HSFs was that this health charity has a strong provincial presence and individuals within the organization are well informed on the best practice recommendations for stroke. Furthermore, this research was funded by the Canadian Stroke Network, which is a Canadian Centre of Excellence that works in partnership with the national HSF office. The HSF is a federation of provincial offices; the national office is linked to, but distinct from, each provincial HSF. The Atlantic Provinces were chosen to participate in the research project for the following reasons: they had not yet implemented the recommendations for coordinated stroke care, their healthcare systems are relatively resource-challenged compared with the rest of Canada, and population-based studies have shown these provinces to have a high prevalence of older persons, who have an elevated risk of stroke (Colman and Hayward 2003).

\section{Description of intervention}

The intervention is outlined in Table 1. Briefly, it entailed hiring knowledge brokers and creating networks outside, across and within each province. Generally, the links outside of Atlantic Canada provided information on what was happening in other Canadian jurisdictions. Links across the four provinces provided support for the knowledge brokers, and links within the provinces disseminated information on the best practice recommendations within the healthcare system.

The research project was funded by the Canadian Stroke Network and lasted from October 2003 to December 2005. The network outside the Atlantic Provinces consisted of organizations that had connections to the Canadian Stroke Network. The Canadian Stroke Network had partnered with the national office of the HSF to create the Canadian Stroke Strategy. At the time of our project, the Canadian Stroke Strategy had strong connections with the Ontario HSF and the Ontario Stroke Strategy because that province had successfully implemented coordinated stroke care but had not yet established connections with the HSFs in the Atlantic Provinces. The network the project created across the Atlantic Provinces connected the knowledge brokers to one another, and to the research team based in Nova Scotia. The brokers were embedded in each Atlantic Province and were closely linked with networks within their province.

The first step of establishing the intervention was to create a network within each province. This started with setting up management teams that represented the provincial $\mathrm{DOH}$ and HSF. Setting up the teams involved conducting an initial forum that introduced the project to the provincial organizations and then making trips to each province to get organizational approval for one of their administrators to participate. It took six months to establish 
the teams. It took that long because the host organizations had to commit to participating in the project for three years, the team members were not paid and the DOH had to identify which administrator should represent the organization. After the management teams were established, they worked with the researchers to identify province-specific goals that would be achieved by the end of the research project.

TABLE 1. Details of the knowledge-exchange intervention

\begin{tabular}{|c|c|c|}
\hline Intervention Component & Composition & Responsibilities \\
\hline Knowledge Broker & $\begin{array}{l}\text { Person located in each of the provinces, } \\
\text { worked part-time, sometimes also worked } \\
\text { for host organization. } \\
\text { Hired within 9-14 months from start of } \\
\text { project. }\end{array}$ & $\begin{array}{l}\text { Interfaced with the network; key person } \\
\text { responsible for achieving the provincial } \\
\text { goals; main access person for stroke } \\
\text { research evidence. }\end{array}$ \\
\hline \multicolumn{3}{|l|}{ Network Outside the Provinces } \\
\hline $\begin{array}{l}\text { Ontario-based } \\
\text { Ontario Stroke Strategy }\end{array}$ & $\begin{array}{l}\text { Representatives from health facilities and } \\
\text { administrators responsible for implementing } \\
\text { coordinated stroke care. }\end{array}$ & $\begin{array}{l}\text { Presented at face-to-face meetings and } \\
\text { consulted by telephone with knowledge } \\
\text { brokers. }\end{array}$ \\
\hline HSF of Ontario & $\begin{array}{l}\text { Representatives involved with initiating and } \\
\text { creating professional development modules } \\
\text { for the Ontario Stroke Strategy. }\end{array}$ & Consulted with on an as-needed basis. \\
\hline National: Canadian Stroke Strategy & $\begin{array}{l}\text { Representatives from the Canadian Stroke } \\
\text { Strategy who supported implementing } \\
\text { coordinated stroke care across Canada. }\end{array}$ & $\begin{array}{l}\text { Presented at face-to-face meetings; } \\
\text { coordinated national roundtable with } \\
\text { representation from all provinces; consulted } \\
\text { by telephone with knowledge brokers. }\end{array}$ \\
\hline \multicolumn{3}{|l|}{ Network across the Provinces } \\
\hline Regional: Research Team & $\begin{array}{l}\text { Researchers } \\
\text { Coordinator had at least monthly contact } \\
\text { with knowledge brokers and semi-annual } \\
\text { contact with teams. }\end{array}$ & $\begin{array}{l}\text { Coordinated knowledge brokers' monthly } \\
\text { teleconferences and semi-annual face-to- } \\
\text { face meetings; managed research funds; } \\
\text { evaluated research project. }\end{array}$ \\
\hline \multicolumn{3}{|l|}{ Network within Each Province } \\
\hline Management Team & $\begin{array}{l}\text { Two high-level administrators from the } \\
\mathrm{HSF} \text { and } \mathrm{DOH} \text {, to represent the research } \\
\text { partners. } \\
\text { Established within } 6 \text { months from start of } \\
\text { project. }\end{array}$ & $\begin{array}{l}\text { Team members developed provincial goals, } \\
\text { hired the knowledge broker, and attended } \\
\text { semi-annual meetings. } \\
\text { One team member supervised the } \\
\text { knowledge broker on a daily basis. }\end{array}$ \\
\hline Stroke Advisory Group & $\begin{array}{l}\text { Stroke clinicians, health charities, and } \\
\text { healthcare administrators (the composition } \\
\text { was different in each province). } \\
\text { Gathered together on an as-needed basis. }\end{array}$ & $\begin{array}{l}\text { Helped the knowledge brokers reach their } \\
\text { provincial goals; disseminated information on } \\
\text { coordinated stroke care within the province } \\
\text { to districts; and shared processes with other } \\
\text { stroke advisory groups. }\end{array}$ \\
\hline
\end{tabular}

Abbreviations: $\mathrm{HSF}=$ Heart and Stroke Foundation; $\mathrm{DOH}=$ Department of Health

Management teams had flexibility in creating the individual goals they wanted to achieve as long as they could demonstrate that these would help reach the research project's goal of increasing organizational readiness for improving stroke care. The management teams hired the knowledge broker, but the research project paid the brokers' part-time salary and some meeting costs. One member of the team was designated to house and supervise the knowledge broker on a daily basis. Once hired, each broker had the responsibility of facilitating awareness of current 
stroke care and knowledge of the best practice recommendations for coordinated stroke care within the healthcare system. The management team and a stroke advisory group guided the knowledge broker on how best to assimilate the recommendations into the healthcare system.

The second link within the provincial network was a stroke advisory committee. In each province, the stroke advisory group provided connections to individuals who could disseminate the recommendations throughout the healthcare system. The only province that had a pre-existing stroke advisory group was Nova Scotia. This group consisted of stroke clinicians and local HSF representatives. Shortly before the research project began, the Nova Scotia advisory group had presented a strategy document to the DOH to increase the department's awareness of, and advocate for, implementation of the coordinated stroke best practice recommendations (Nova Scotia Integrated Stroke Strategy Committee 2002).

The province-specific research goals, chosen by the management teams, were related to whether the province had a pre-existing stroke advisory committee. Because Nova Scotia already had an advisory group, its management team decided their goal would be to increase awareness of coordinated stroke care in groups whose support would be needed to get government funding to implement the document. The groups they targeted were DOH administrators, regional health authorities across the province and practitioners who did not have specific training to care for persons with stroke (e.g., primary care practitioners, emergency department physicians, nurses).

The goals of the other three provincial management teams were to emulate and improve upon the work done by Nova Scotia. They emulated the work by creating stroke advisory groups and strategy documents that could be presented to their provincial governments. They improved upon the work by creating stroke advisory groups that already had DOH engagement, regional representation and practitioners from outside the speciality of stroke. They believed this would allow them to develop stroke strategy documents with built-in regional and practitioner support, and thus bypass the work currently being done by Nova Scotia. The successful achievement of the management teams' identified goals (to create collaborative strategy documents and to increase support for the previously written strategy document) were believed to support the research project's goal of increasing organizational readiness in the provincial healthcare system for implementing coordinated stroke care.

To facilitate communication among the network members, the researchers set up monthly teleconferences with the knowledge brokers and semi-annual forums with the management teams. The forums included the knowledge brokers and representatives from the outside network, who presented information on coordinated stroke care to the attendees. In addition to these formal modes of communication, the knowledge brokers were encouraged to communicate informally with anyone in the network. Ultimately, the knowledge brokers became provincial representatives of a national roundtable panel that was created by the Canadian Stroke Strategy.

\section{Increasing awareness about the need to improve care}

To increase the provincial healthcare system's awareness of the need to improve stroke care, the 
research project gathered information on the provincial characteristics of the Atlantic Provinces regarding stroke care so that it could be communicated within the network. Three forms of data were collected: census data from Statistics Canada, administrative data from the Canadian Institute of Health Information (CIHI) and a survey of stroke care services provided in acute care facilities. The 2001 census data were used to describe the urban-rural balance of the provinces. The census data depicted these provinces as primarily rural, each with one large urban centre comprising $17 \%$ to $41 \%$ of the population, with the rest of the population distributed throughout the province. The CIHI data were used to determine the number of cases of stroke per hospital (sometimes called hospital separations). The number of cases were identified in the CIHI Discharge Abstract Database for acute care services as cases that were given a Most Responsible Diagnosis of stroke (International Classification of Diseases [ICD] version 10 codes I60, I61, I63 and I64, or ICD-9 codes 430, 431, 434 and 436). The CIHI data showed that the average number of stroke cases for the provinces ranged from 1,150 to 1,263.

To identify where stroke care could be improved by implementing best practice recommendations, a survey was conducted in all four provinces at the beginning of the project (20042005) with hospitals that provided acute care services for stroke. The survey was adapted from one conducted earlier in Ontario ( Tu and Porter 1999). It contained 22 questions about acute care services provided when someone was admitted because of a stroke and the rehabilitation services that were available outside the hospital (e.g., the availability and accessibility of health professionals, diagnostic imaging and other services that are part of coordinated stroke care). All hospitals that delivered acute care services to patients with stroke identified an individual within their organization to complete the questionnaire. This process was facilitated by the involvement of team members from the $\mathrm{DOH}$ who had contacts working in these facilities. This approach ensured that the surveys were completed by the most appropriate person and that the surveys were returned. The knowledge broker in each province took responsibility for distributing the surveys and having each person who filled out the survey sign a consent form.

Information gathered in the survey helped identify areas where current stroke care was below the recommended standards of care. The survey results presented in Table 2 are an aggregate of all four provinces to protect the confidentiality of individual hospitals, owing to the small sample sizes.

The survey showed that acute care for stroke was better in large urban tertiary care hospitals, but there were no designated stroke centres outside of these urban areas. Protocols for treating persons with stroke in non-designated stroke centres were not in place. These included emergency department protocols to facilitate timely care of persons with stroke, bypass protocols to ensure that persons with stroke were taken to a designated stroke centre, and mechanisms to provide persons post-acute stroke access to in-patient rehabilitation services. The information from the census, administrative data and survey were used by the advisory groups to develop strategy documents and identify where resources needed to be allocated to improve stroke care. 
TABLE 2. Results of stroke survey for the Atlantic Provinces

\begin{tabular}{|c|c|}
\hline & $\%$ of Hospitals Responding \\
\hline Survey response rate & $93 \%(102 / 110)$ \\
\hline Hospitals not providing thrombolytic therapy in their emergency departments & $81 \%(n=83 / 102)$ \\
\hline $\begin{array}{l}\text { Of those who did not offer thrombolytic therapy for stroke, the } \% \text { that transferred } \\
\text { patients to another location }\end{array}$ & $48 \%(n=40 / 83)$ \\
\hline $\begin{array}{l}\text { Of those that transferred patients to another location, the } \% \text { when other location was } \\
\text { more than } 30 \text { minutes away }\end{array}$ & $80 \%(n=66 / 83)$ \\
\hline Protocols not in place to provide access to care for acute stroke patients & $77 \%(n=79 / 102)$ \\
\hline No on-site access to internist & $66 \%(n=67 / 102)$ \\
\hline No on-site access to neurologist & $88 \%(n=90 / 102)$ \\
\hline No on-site access to nurses with specialty training in neurology & $90 \%(n=92 / 102)$ \\
\hline $\begin{array}{l}\text { Of the } 42 \% \text { who responded to the question about occupational therapists, the } \% \text { that } \\
\text { had no occupational therapist dedicated to the care of stroke patients }\end{array}$ & $78 \%(n=36 / 46)$ \\
\hline $\begin{array}{l}\text { Of the } 51 \% \text { who responded to the question about physiotherapists, the } \% \text { that had no } \\
\text { physiotherapist dedicated to the care of stroke patients }\end{array}$ & $76 \%(n=40 / 52)$ \\
\hline Stroke patients managed on general medical ward rather than a stroke unit & $89 \%(n=91 / 102)$ \\
\hline Stroke patients with access to coordinated interdisciplinary care & $19 \%(n=19 / 102)$ \\
\hline Stroke patients admitted to a stroke unit & $4 \%(n=4 / 102)$ \\
\hline If no stroke unit available in the facility, the patients are clustered on one ward & $5 \%(n=5 / 102)$ \\
\hline $\begin{array}{l}\text { Percentage of facilities where the estimated wait time to be admitted to an in-patient } \\
\text { rehabilitation facility was over a month }\end{array}$ & $20 \%(n=20 / 102)$ \\
\hline
\end{tabular}

\section{Methods to evaluate the knowledge-exchange intervention}

To evaluate the knowledge-exchange intervention, we conducted in-depth interviews with the management teams and knowledge brokers lasting one to two hours. Each member $(n=8)$ of the management team participated in an interview in years one and two of the project. Each knowledge broker $(n=4)$ participated in an interview and a focus group (with all four brokers) in year two of the project. The interviews $(n=20)$ and focus group were audiotaped, professionally transcribed and imported into qualitative data analysis software, NVivo version 2.0. All transcripts were sent back to participants for member checking to ensure accuracy of the quotations. Transcripts were reviewed for emerging themes, using an iterative process. Open coding was used to identify clusters of agreement or disagreement under the identified themes (Creswell 1998; Miles and Huberman 1994). Two researchers independently examined and coded the qualitative data, which were then reviewed in a group, comprising both coders and a third researcher, to reach consensus on final coding decisions. After the interviews were coded and the initial themes had been identified, the themes were compared with components in Greenhalgh's model of diffusion in service organizations. The intent was to explore the connections between the themes that evolved from the research project to markers of organizational readiness (Greenhalgh et al. 2004). Quotations from the transcribed interviews were included within each theme. 
In addition to evaluating the intervention through qualitative data, the research project monitored and collected documents that helped evaluate whether each province achieved its identified goals. These documents included minutes taken during monthly teleconferences with knowledge brokers and semi-annual meetings with management teams and brokers. These minutes were shared with attendees to ensure accuracy of the documented information. In addition, at the end of the research project the provincial teams supplied copies of their completed strategy documents.

\section{Findings}

The minutes from the teleconferences and meetings documented the challenges and successes of the management team and knowledge brokers as they worked toward achieving their goals. The minutes showed that $\mathrm{DOH}$ representatives met regularly with their superiors, such as the associate deputy ministers or deputy ministers of health, to brief them on the progress of the research project. A challenge mentioned in one of the teleconferences was the creation of bypass protocols that would allow local hospitals to be bypassed so that patients could be taken to a designated stroke hospital. There was a lack of support for the protocol in the regions because it would change the distribution of patients with stroke among hospitals, which could mean a loss of revenue to a bypassed hospital. To address this challenge, knowledge brokers personally delivered the stroke survey results to regional administrators so that they could talk with them about the bypass protocol. The knowledge brokers felt that initiating this dialogue contributed to an increase in regional support for the stroke strategy document.

The qualitative evaluation of the knowledge-exchange intervention identified three major themes: healthcare system challenges to implementing coordinated stroke care, positive attributes of the knowledge-exchange intervention, and intervention outcomes that enhanced organizational readiness for coordinated stroke care (Table 3). The sample quotations chosen for the themes are identified by participant type (knowledge broker [KB], Heart and Stroke Foundation $[\mathrm{HSF}]$ partner, or Department of Health $[\mathrm{DOH}]$ partner) and a number from 1 to 4 assigned to each province. In the interest of space, only a small sample of individual quotations are presented in Table 3 to illustrate informant responses within each theme. The quotations indicate that the knowledge-exchange intervention helped link key individuals within the healthcare system, and that these links facilitated these people's awareness of the best practice recommendations. Once aware, these individuals identified ways to integrate stroke care improvements into their organizational mandates. For example, members of the stroke advisory groups disseminated information on the best practice recommendations within their regions and in their practices, while the management team members identified recommendations that their organization could take the lead in implementing (HSF concentrated on the prevention of stroke; the $\mathrm{DOH}$ concentrated on acute and primary care).

The goals articulated by each of the management teams were achieved by the end of the research project. Three provincial teams created stroke advisory groups and collaborative strategy documents. These documents were formerly presented to their respective provincial 
governments to advocate for funding. Subsequently, the DOHs have used the strategic documents to make evidence-informed changes to stroke care in their healthcare systems. The evidence that Nova Scotia met its goal is less concrete, but the team felt they had improved support for their strategy document within the healthcare system. As evidence of this, after the research project was completed the Nova Scotia team saw their DOH hire the knowledge broker to continue working on coordinated stroke care; their provincial government allocated funding to a rural health region for a coordinated stroke demonstration project; and a province-wide cardiovascular health program was established to monitor stroke care.

TABLE 3. Summary of qualitative themes and sample quotations

\begin{tabular}{|c|c|c|}
\hline Theme Title & Summary of Theme & Representative Quotation \\
\hline \multicolumn{3}{|c|}{ A. Healthcare System Challenges } \\
\hline Limited funds & $\begin{array}{l}\text { One of the most constant themes in the data was } \\
\text { the challenge of meeting health service needs } \\
\text { with limited funds in smaller healthcare systems. } \\
\text { Perceived lack of motivation to invest provincial } \\
\text { funds without concurrent federal funding. }\end{array}$ & $\begin{array}{l}\text { DOH \#2: And if we add resources to the stroke } \\
\text { strategy, what do we stop doing? } \\
\text { HSF \#3: Resources are huge ... now it is obesity } \\
\text { and physical activity. That is where the money is } \\
\text { right now... And that is what you do. And you do } \\
\text { that for a couple of years until the money swings } \\
\text { around to another risk factor. }\end{array}$ \\
\hline No tension for change & $\begin{array}{l}\text { Stroke not on the public radar as a condition. } \\
\text { Individuals unaware of advances in stroke } \\
\text { treatment. } \\
\text { Resistance to change of any kind. }\end{array}$ & $\begin{array}{l}\mathrm{KB} \# \text { I : And I have found ... what I would have } \\
\text { to call a negative attitude about stroke patients in } \\
\text { general. But I have had people just say with a little } \\
\text { nuance in their voice, "Well, the poor old dears."' }\end{array}$ \\
\hline $\begin{array}{l}\text { Time to make health system } \\
\text { changes }\end{array}$ & $\begin{array}{l}\text { Time necessary for the healthcare system to } \\
\text { make evidence-informed improvements in } \\
\text { healthcare. }\end{array}$ & $\begin{array}{l}\mathrm{KB} \# \text { I : ... I have averaged it out to about } 7 \text { years } \\
\text { from the time an issue is raised and brought to } \\
\text { our Department of Health, from then until actual } \\
\text { change is happening. }\end{array}$ \\
\hline $\begin{array}{l}\text { Perceived complexity of } \\
\text { coordinated stroke care }\end{array}$ & $\begin{array}{l}\text { Coordinated stroke care is complex to explain } \\
\text { (it needs to be broken down into separate } \\
\text { components). }\end{array}$ & $\begin{array}{l}\text { DOH \# I: So which components of an integrated } \\
\text { stroke strategy are we talking about? Is there } \\
\text { evidence? Depending on which of these components } \\
\text { that we are going to focus on, then we will explore } \\
\text { the research evidence related to that. }\end{array}$ \\
\hline $\begin{array}{l}\text { Time required to build social } \\
\text { networks }\end{array}$ & $\begin{array}{l}\text { Time to get volunteers for Stroke Advisory } \\
\text { Group. }\end{array}$ & $\begin{array}{l}\mathrm{DOH} \# 3 \text {...you've got to work with the players. } \\
\text { You know everyone is very, very busy and the people } \\
\text { that we meet at the table are the busiest in the } \\
\text { province. }\end{array}$ \\
\hline $\begin{array}{l}\text { Need for support from health } \\
\text { regions }\end{array}$ & $\begin{array}{l}\text { For the provincial healthcare system to } \\
\text { implement coordinated stroke care, they needed } \\
\text { support from the health regions in the province } \\
\text { so that they would implement the recommended } \\
\text { changes. }\end{array}$ & $\begin{array}{l}\text { DOH \# I: There needs to be an interest at the } \\
\text { [region] and a willingness and an understanding of } \\
\text { how it integrates into work that they currently do, } \\
\text { and how they can do what they do better. }\end{array}$ \\
\hline \multicolumn{3}{|l|}{ B. Intervention Attributes } \\
\hline Knowledge broker qualities & $\begin{array}{l}\text { Background in health. } \\
\text { Good communication and relationship-building } \\
\text { skills. } \\
\text { Equally effective from within or outside } \\
\text { government. }\end{array}$ & $\begin{array}{l}\text { DOH \# I: ... I see that person [knowledge broker] } \\
\text { as a key liaison between the partners in fostering } \\
\text { communication, in identifying various perspectives } \\
\text { and helping to develop and enhance that } \\
\text { partnership ... It still hinges around a key person } \\
\text { that can act as a facilitator, an enabler of change. }\end{array}$ \\
\hline
\end{tabular}


TABLE 3. Continued

\begin{tabular}{|c|c|c|}
\hline $\begin{array}{l}\text { Incentive to focus on improving } \\
\text { stroke care }\end{array}$ & $\begin{array}{l}\text { Research project created an incentive to initiate } \\
\text { coordinated stroke care. }\end{array}$ & $\begin{array}{l}\text { HSF \#2: If it weren't for this research project we } \\
\text { wouldn't be doing this work right now. We would be } \\
\text { trying to do this work, but we wouldn't be doing it in } \\
\text { the way that we are doing it right now. }\end{array}$ \\
\hline Supportive networks & $\begin{array}{l}\text { Clustering the provinces regionally increased their } \\
\text { national presence and ability to learn from one } \\
\text { another. }\end{array}$ & $\begin{array}{l}\text { KB \#3: ... I think it would be very isolating to have } \\
\text { done this actually ourselves ... I have learned from } \\
\text { discussions we have had and information they share } \\
\text { with me. }\end{array}$ \\
\hline Information networks & $\begin{array}{l}\text { Connections outside the region informed the } \\
\text { management teams and knowledge brokers } \\
\text { about how to implement BPRs. }\end{array}$ & $\begin{array}{l}\text { DOH \#2: I think the forums were very helpful. } \\
\text { Because I did not know a lot about stroke care. }\end{array}$ \\
\hline \multicolumn{3}{|l|}{ C. Intervention Outcomes } \\
\hline $\begin{array}{l}\text { Improved relationships among } \\
\text { partners }\end{array}$ & $\begin{array}{l}\text { Relationships between partners were improved } \\
\text { and sustainable after research project ended. }\end{array}$ & $\begin{array}{l}\text { DOH \# I: .... It was just having that little bit more } \\
\text { support and somebody who was dedicated to make } \\
\text { those partnerships that was absolutely critical ... } \\
\text { I think the relationship between the partners was } \\
\text { rocky at best in the beginning because of the ... } \\
\text { lack of understanding and respect for each person's } \\
\text { role... But I have no doubt that the Department } \\
\text { will continue to work with the Heart and Stroke } \\
\text { Foundation. }\end{array}$ \\
\hline $\begin{array}{l}\text { Implemented components of } \\
\text { coordinated stroke care into } \\
\text { existing programs }\end{array}$ & $\begin{array}{l}\text { Deconstructed coordinated stroke care into } \\
\text { components that would align with existing } \\
\text { provincial programs. }\end{array}$ & $\begin{array}{l}\text { DOH \#4: ... as we have been developing the } \\
\text { strategy, we have been meeting with individuals who } \\
\text { have certain program responsibilities ... and trying } \\
\text { to integrate it into as much as existing sort of areas } \\
\text { of concentration that we are doing right now. }\end{array}$ \\
\hline $\begin{array}{l}\text { Increased awareness of how to } \\
\text { assimilate BPRs into the healthcare } \\
\text { system }\end{array}$ & $\begin{array}{l}\text { Research project increased participants' } \\
\text { awareness of the BPRs and strategies for } \\
\text { increasing evidence-informed healthcare. }\end{array}$ & $\begin{array}{l}\text { HSF \#2: I think I knew Nova Scotia had been } \\
\text { doing some work on preparing a document, but } \\
\text { the specifics of the document, the process they } \\
\text { followed, the actual documents, all of that kind of } \\
\text { stuff I learned through the project. }\end{array}$ \\
\hline Increased dissemination of BPRs & $\begin{array}{l}\text { Increased dissemination of BPRs within the } \\
\text { provincial healthcare systems. }\end{array}$ & $\begin{array}{l}\text { DOH \#4: ... I think that everyone thinks the key } \\
\text { outcome of this project is going to be the stroke } \\
\text { strategy. But you know what? Some of the key } \\
\text { outcomes of this project are already happening ... } \\
\text { It's so interesting, just by starting to talk about what } \\
\text { should be happening in the system here, and having } \\
\text { the right players at the table [advisory group] ... } \\
\text { the quality of care is being improved as we speak. }\end{array}$ \\
\hline
\end{tabular}

Abbreviations: $\mathrm{KB}=$ Knowledge broker; $\mathrm{HSF}=$ Heart and Stroke Foundation partner; $\mathrm{DOH}=$ Department of Health partner; $\mathrm{BPRs}=$ best practice recommendations

The Canadian Stroke Strategy national roundtable discussions that the brokers participated in during the research project provided an opportunity for the brokers to share strategies they had used in their provinces to improve stroke care. The Canadian Stroke Strategy used these strategies, and information from our research findings, to establish similar knowledge broker positions in provinces that did not have coordinated stroke care. Data from our survey became part of their national data on stroke care services. After our research project ended, two of the Atlantic HSFs received additional funding from the Canadian Stroke Network to train clinicians in the best practice recommendations. 


\section{Challenges}

An important outcome from the research project was the creation of links between the HSF and the $\mathrm{DOH}$, and among members of the stroke advisory group. During the project these links disseminated information on best practice recommendations and stimulated collaboration among the research partners. A great deal of time at the beginning of the project was spent building committed management teams that had key decision-maker representation, and then hiring knowledge brokers to work within these teams. This work was crucial to embedding the intervention within each provincial healthcare system. However, it took six months to get the teams established and between nine and 14 months for the teams to hire the brokers. Factors contributing to this delay were political change (e.g., provincial governments changed in two provinces, and major restructuring occurred in three DOHs), confidentiality concerns (e.g., the DOH was restricted as to how it could work with the HSF because it was perceived to be an advocacy organization) and the low priority of stroke within the provincial governments. Secondly, to create stroke advisory groups the knowledge brokers spent a significant amount of time recruiting change agents who had the knowledge and power to make recommended changes in stroke care in their province. Individuals in the groups represented health regions across the province and provided clinical expertise across the continuum of stroke care. The time spent establishing teams and recruiting people for the groups left less time for the knowledge brokers to achieve their goals within the time frame of the research project.

Finally, the naturalistic setting of the research project created a situation in which external factors both facilitated and hindered teams' abilities to reach their goals. For example, the Canadian Stroke Strategy's commitment to establish a national stroke strategy by the year 2010 supported the research project's goals (Canadian Stroke Strategy 2008), whereas provincial budget cuts and changes in political leadership hindered the establishment of the management team. Although these events make it difficult to attribute our outcomes solely to our intervention, we feel they also indicate that the work we have done has contributed to "real" change in the participating provinces. Our qualitative results show that participants had an increased awareness about the need to improve stroke care and knowledge of best practice recommendations. Also, our findings indicate that study participants stimulated similar changes among their colleagues. Such success hopefully increased their confidence that they could improve stroke care in their province.

\section{Lessons learned}

Our findings confirm elements that have been identified previously in Greenhalgh's conceptual model describing the diffusion of innovations in healthcare organizations (Greenhalgh et al. 2004). This model groups the determinants of innovative change into several areas, such as the qualities of the innovation that facilitate or hinder the healthcare system's adoption of the intervention, system readiness for change and the need for linkages among individuals who are knowledgeable about the innovation and the healthcare organization. Participants in our 
research project described the innovation (coordinated stroke care) as being complex, and the health system readiness for improving stroke care as being low. These factors have been identified by Greenhalgh and colleagues (2004) as barriers to innovative change. In addition, Greenhalgh's model identified that linkages between individuals and organizations facilitated implementation of innovations. The findings from our project imply that the linkages among individuals who were knowledgeable about coordinated stroke care (e.g., researchers, Canadian Stroke Strategy, Ontario HSF and Atlantic Canada HSF) and representatives from the healthcare organizations (e.g., DOH representatives, regional health administrators) created by our knowledge-exchange intervention did facilitate an understanding of coordinated stroke care.

Our findings also replicate the findings by the Promoting Action on Research Implementation in Health Services researchers, which showed that appropriate facilitation strategies can improve the context for implementing evidence in practice (Kitson et al. 1998). In other words, if the context within the provincial healthcare system is not conducive to implementing best practice recommendations, a facilitation strategy might convince decisionmakers that the evidence is strong and that their healthcare system can accommodate the changes necessary for implementation. The knowledge-exchange intervention did improve the context for implementing the best practice recommendations for stroke.

\section{Limitations and strengths}

There are limitations to our findings attributable to the context in which our study was conducted. The provinces that participated in this project were more rural and more resourcechallenged than other Canadian provinces. These factors may have magnified our challenges, and our findings might therefore be transferable only to other rural regions that face similar resource constraints.

The collaborative nature of the research project was an important contributor to the success of the intervention. This aspect affirms Lavis's recommendation that low-resourced health systems collaborate with other organizations and stakeholders to increase their ability to make evidence-informed changes (Lavis et al. 2008). The involvement of decision-makers in our knowledge-exchange intervention improved their awareness of the best practice recommendations. In addition, the collaborative nature of the project increased communication, respect and trust among participants. Knowledge brokers worked with health system representatives to find opportunities for incorporating recommendations into provincially funded initiatives, thus gradually establishing coordinated stroke care.

Establishing networks around the knowledge brokers enhanced their ability to make evidence-informed changes in stroke care within their provinces. This finding extends earlier research that hypothesized that creating such networks may increase support for applying research to practice (Dobbins et al. 2009). Embedding the knowledge brokers within the provincial healthcare systems increased their credibility with practitioners and improved the sustainability of their work after the research project was complete. Networks within the province acted as communities of practice ( $\mathrm{Li}$ et al. 2009) focused on coordinated stroke care, 
creating venues for ongoing contact and providing opportunities for diverse members to find common ground. Knowledge brokers who work in isolation without a supportive network may not be as effective.

\section{Conclusion}

Our project successfully increased organizational readiness within the provincial healthcare systems for implementing the best practice recommendations. It created a demand to improve stroke care, increased awareness of how to implement the recommendations, and established links among individuals and organizations to support implementation. Although the best marker to demonstrate evidence-informed stroke care is improvement at the patient level (McCormack et al. 2002), organizational readiness is an important precursor to making health system changes that result in improved patient outcomes. Our intervention was successful in four different provincial healthcare systems. This success implies that similar knowledgeexchange interventions might work for other medical conditions when implemented in jurisdictions that are rural and resource-challenged.

\section{ACKNOWLEDGEMENTS}

Our thanks to Corinne Corning for her review of the manuscript.

Correspondence may be directed to: Grace Warner, Associate Professor, School of Occupational Therapy, Dalhousie University, 5869 University Ave., Halifax, NS B3H 3J5; tel.: 902-494-2559; fax:902-494-1229; e-mail: grace.warner@dal.ca.

\section{REFERENCES}

Canadian Stroke Strategy. 2008 (December 2). “Canadian Best Practice Recommendations for Stroke Care.” Canadian Medical Association Journal 179(12 Suppl.): E1-E93.

Colman, R. and K. Hayward. 2003. The Tides of Change. Addressing Inequity and Chronic Disease in Atlantic Canada: A Discussion Paper. Halifax: Health Canada Population and Public Health Branch, Atlantic Regional Office.

Contractor, N.S. and P.R. Monge 2002. "Managing Knowledge Networks." Management Communications Quarterly 16(2): 249-58.

Creswell, J.W. 1998. Qualitative Inquiry and Research Design: Choosing among Five Traditions. Thousand Oaks, CA: Sage.

Denis, J.L. and J. Lomas. 2003. "Convergent Evolution: The Academic and Policy Roots of Collaborative Research." Journal of Health Services Research and Policy 8(2 Suppl.): S21-S26.

Dobbins, M., P. Robosen, D. Ciliska, S. Hanna, R. Cameron, L. O’Mara, K. DeCorby and S. Mercer. 2009. "Description of a Knowledge Broker Role Implemented as Part of a Randomized Controlled Trial Evaluating Three Knowledge Translation Strategies." Implementation Science 4(23). doi:10.1186/1748-5908-4-23.

Greenhalgh, T., G. Robert, F. Macfarlane, P. Bate and O. Kyriakidou. 2004. “Diffusion of Innovations in Service Organizations: Systematic Review and Recommendations." Milbank Quarterly 82(4): 581-629. doi:10.1111/ j.0887-378X.2004.00325.x.

Kitson, A., G. Harvey and B. McCormack. 1998. "Enabling the Implementation of Evidence Based Practice: A Conceptual Framework." Quality and Safety in Health Care 7(3): 149-58. 


\section{Grace Warner et al.}

Lavis, J., A. Oxman, R. Moynihan and E.J. Paulsen. 2008. “Evidence-Informed Health Policy 1 - Synthesis of Findings from a Multi-Method Study of Organizations That Support the Use of Research Evidence." Implementaton Science 3(53). doi:10.1186/1748-5908-3-53.

Li, L.C., J.M. Grimshaw, C. Nielsen, M. Judd, P.C. Coyte and I. Graham. 2009.“Use of Communities of Practice in Business and Health Care Sectors: A Systematic Review." Implementation Science 4(27). doi: 10.1186/1748-59084-27.

Lindsay, P., M. Bayley, A. McDonald, I. Graham, G. Warner and S. Phillips. 2008.“Toward a More Effective Approach to Stroke: Canadian Best Practice Recommendations for Stroke Care." Canadian Medical Association Journal 178(11): 1418-25.

Lomas, J. 2000. “Using 'Linkage and Exchange' to Move Research into Policy at a Canadian Foundation." Health Affairs 19(3): 236.

McCormack, B., A. Kitson, G. Harvey, J. Rycroft-Malone, A. Titchen and K. Seers. 2002. “Getting Evidence into Practice: The Meaning of 'Context." Journal of Advanced Nursing 38(1): 94-104.

Miles, M. and A.M. Huberman. 1994. An Expanded Sourcebook: Qualitative Data Analysis (2nd ed.). Thousand Oaks, CA: Sage.

Nova Scotia Integrated Stroke Strategy Committee. 2002. Re-organizing Stroke Care in Nova Scotia. Halifax: Heart and Stroke Foundation of Nova Scotia.

Tu, J. and J. Porter. 1999. Stroke Care in Ontario: Hospital Survey Results. Toronto: Institute for Clinical Evaluative Sciences.

Weiner, B.J. 2009. “A Theory of Organizational Readiness for Change." Implementation Science 4(67). doi:10.1186/1748-5908-4-67.

Weiner, B.J., H. Amick and S.D. Lee. 2008. “Conceptualization and Measurement of Organizational Readiness for Change: A Review of the Literature in Health Services Research and Other Fields." Medical Care Research and Review 65(4): 379-456. 